for the nation as a whole if vital historical information as well as electronic information, which is just in the development stages, should be preserved. Librarians must continue to sponsor programs to increase the public's awareness of the urgency of the preservation problems. Public and private funding sources should be mobilized to support adequate preservation programs to conserve the nation's information base.-Hannelore B. Rader, ACRL President.

\title{
The expanding universe of special formats
}

\author{
By Margaret E. Galloway \\ Associate Director of Libraries \\ North Texas State University
}

\author{
Kenneth Lavender \\ University Bibliographer \\ North Texas State University
}

\author{
George Mitchell \\ Director, Media Library \\ North Texas State University
}

and William Floyd

Systems Development Librarian

North Texas State University

\section{Some local strategies for collection development of computer software.}

I sity Libraries received several requests for computer software. Since the libraries had never purchased this type of material, the administration appointed a committee to investigate the matter and make recommendations. Two issues were of immediate concern: the considerable expense involved in the purchase of such materials including the necessity for special handling, and the need to provide accessibility of the material to our patrons.

Both of these concerns had far-reaching implications. It was obvious that such materials tended to be extremely expensive, difficult to evaluate for purchase, time-consuming to catalog, and required special, diverse equipment to access. For insight into the problems, the committee decided to review the literature then available, but the review provided only limited assistance. Next the committee issued a questionnaire to be sent to a select group of libraries in the United States and Canada. Analysis of the responses to the questionnaire simply accented the general lack of information on how to deal with machine-readable formats as library materials. $^{2}$

${ }^{1}$ The questionnaire was sent to 100 academic and research libraries: the 50 libraries identified from statistics of Southern college and university libraries published by Louisiana State University Library; and the 50 largest libraries from the current ARL listing not included in the first 50 . Forty-eight libraries provided usable responses to all questions.

${ }^{2}$ SPEC Kit \#123, Microcomputer Software Poli- 
At this point, the committee agreed that it must take the philosophical stance that information, regardless of format, should be collected by an academic library if it is important to the educational goals of the university. Since this decision would impact the outdated collection policy of the NTSU Libraries, it was proposed that the collection policy be revised to reflect the need to collect computer software. As it worked on its recommendations, the committee determined that no previous attempt had been made to define the primary clientele of the Libraries. As a state institution, the Libraries receive all funding as an appropriation from the state legislature, based on a formula of student credit hours that allocates more money for doctoral and master's hours than for undergraduate hours. No funds are directly allocated for faculty, staff, or the community whose taxes support the institution.

It is also true, however, that without the research of the graduate faculty there would be no master's or doctoral students and that the community has always had access to the Libraries' collections. The committee defined primary clientele as "Persons with an official connection to... (the) University, including students, faculty, and staff." The definition of primary clientele was immediately adopted as a part of a policy that defined the principles for services in the Libraries and thus also adopted as part of the revised collection development policy. While seemingly a simple decision, it formed the basis for all recommendations made by the committee. For example, the committee determined that having material no one could access, or having material simply to have the format, was not appropriate to these principles. More specifically, it opposed the idea of purchasing computer software that could be used by only one faculty member for a specific research project. Thus these principles have already had application in the development of the Libraries' collections.

Selection guidelines for computer software and data files now have been written and appended to the general collection development policy of the Libraries. ${ }^{3}$ The guidelines basically state that because of the high cost of these materials, and the importance of developing a well-used collection, all decisions to purchase are made with great care. Either a preview of the material is performed by the faculty requesting it, or reviews are located

cies in ARL Libraries (April 1988), was not available at the time of the survey. The results of its own survey, however, indicated that only $34 \%$ of the responding libraries had policies or were in the process of creating them. "Moreover, there is some concern that by not assimilating this new medium, libraries might be abdicating a significant role in the information age."

${ }^{3}$ Appendix $C$ and D of the North Texas State University Libraries' Collection Development Policy are appended. that adequately assess its potential. The cost of cataloging and storage is taken into consideration. Materials for microcomputer use and for both mini- or main-frame computer use must be shown to support curriculum or research needs. Frequently these requests relate directly to the University's stated goals and mission to respond to the growing hi-tech needs of the Dallas/Fort Worth metroplex.

Funding for purchases has come from a variety of sources: the computing center, gifts, and the library materials fund. It is now clear from our experience that each party to the purchase must work closely and cooperatively in order to insure the best use of limited funds. To track the location of software on campus, and yet to make the tools of instruction and research as widely available as possible, the Libraries are working with the University Computing Council toward a system that will exert control over the proliferation of software and databases on campus. A master backup copy of microcomputer software and data files is housed in the Media Library, but the circulating copies and documentation are made available in the area where the material is to be used.

Software and data files for use on the mini- and main-frame computers in the computing center are housed in the center's tape handling facility. The facility has its own management and utilization control system to locate tapes and keep data on them from deteriorating, but this system does not replace cataloging by the Libraries. All librarycataloged materials in the computing center are listed in the Virginia Tech Library System (VTLS) online catalog of the Libraries and are accessible to the Libraries' primary clientele through the computing center.

Indeed, anyone with a terminal anywhere on campus can dial into the center through the campus local area network and use any of the software or data files cataloged in the Libraries. Copies of documentation are also cataloged and available in the appropriate reference or reserve area of the Libraries.

Standardization, user convenience, and copyrights and license agreements were concerns that required a university-wide approach. Because the Libraries have defined the primary clientele, established a flexible collection development policy, and laid the groundwork for cooperative acquisition and use of software and data files, they are now part of the university's decision-making process. Thus, the Libraries have created means which respond to the access needs of patrons, using university-wide facilities, rather than attempting to rely mainly upon their own. While these means may not be traditional library methods of operation, they have proven effective. By being concerned at a relatively early date about the issues surrounding computer software and data files, the Libraries have a strong position in building a coop- 
erative campus-wide software and data file network.

\section{APPENDIX C}

\section{NTSU Guidelines for selection of computer software}

As the technology of data storage changes, research libraries must be committed to providing access to all types of information regardless of format. Usually, one considers computer software as the programs used to operate a computer and manipulate stored, coded data. For the purpose of these guidelines, the committee included not only the former meaning but also the concept of machine readable data files (hereafter MRDF). MRDF is any collection of data, text and/or numeric, that can be accessed and/or manipulated by computer. For these guidelines, the Libraries" primary clientele remains students, faculty, and staff.

\section{A. Factors affecting acquisition}

Before acquiring computer software, one must consider several issues. These issues include consortium and contractual agreements and the need to provide access to this type of informational source. Standard collection development considerations remain important. However, there are additional factors specific to this format of data storage which affect decisions concerning acquisition.

1. Subject scope. As with other materials, textual and numeric data files must be evaluated in relationship to the instructional and research interests of the academic community.

2. User need. The information needs of academic users must be examined to determine if primary data is needed in this format. Some users may need to manipulate primary data, rather than use already manipulated data. Conversely, some users may not need to deal with data manipulation and its attendant problems.

3. Uniqueness of data. As information sources proliferate, it becomes imperative to examine the uniqueness of data in this format. If the data is also available in other formats, in which format(s) should this data be acquired? There often are reasons to have access in more than one format.

4. Authority of data. The origins of the data should be examined to assess authoritativeness and completeness. Data representing research in progress which might eventually undergo significant change is perhaps of limited value.

5. Confidentiality of data. Some textual and numeric data files may include proprietary or restricted information and consequently may be limited in terms of the $\mathrm{Li}$ braries' primary clientele. Some files may have suppressed information to insure confidentiality.

6. Physical format. In these times of rapid technological change, a variety of physical formats may be available. Some materials available on magnetic tape are also available in floppy disc, disc pack, or optical disk format.

7. Online access. Some sources are available only online. For business and industry statistics, online access provides immediate forecasting capabilities. While most data sources are not available in this fashion. it is conceivable that more will become available as the need and demand for this type of information grows

8. Documentation, consulting and instructional support, and software. Using textual and numeric data files requires adequate documentation so users can extract needed information. Complex files may require staff to as- sist users with file manipulation. Hardware and software issues must also be addressed, including availability of computing facilities and software within the campus community.

9. Extent of utilization. The extent to which the material is expected to be used as judged by expressed interest, number of classes to which appropriate, quality of content, and technical quality.

10. Duplication. The need for duplication of heavily used items and for replacement of damaged items.

11. Cooperative acquisition. Purchase decisions should consider the accessibility of materials within the North Texas area.

12. Contracts. All contracts should be negotiated with provisions for the broadest possible use by the Libraries' primary clientele.

\section{B. Documentation}

The successful use of computer software as well as successful searches of MRDF often depend upon understanding the methods by which the software works and the methods by which the data was coded. This implies that the documentation must be available to the users. Therefore, the Libraries should serve as the central repository of information related to any computer software acquired. These items would include but are not limited to:

1. published directories of data files and guides to the holdings of data archives which identify the existence and availability of these resources;

2 . core collections of periodicals and monographs devoted to the utilization of these materials; and

3. code books, systems manuals, and other documentation, if appropriate.

This documentation should circulate to all users. However, because of heavy demand, it may be necessary to limit the access or length of the borrowing period for some items.

\section{Policies}

1. Generally, the NTSU Libraries will acquire computer software only where the magnitude of the research project or teaching warrants the expenditure of time, effort, and moner.

2. The Libraries will also maintain annually updated MRDF on a limited basis.

3. Requests for items not broadly or intensively useful will receive a lower priority.

4. The NTSU Libraries will not acquire MRDF that, under contractual agreements, can only be used by one person. Any MRDF obtained must be, at the very least, in some way accessible to any member of the Libraries primary clientele.

5. Also excluded are such MRDF that by virtue of their content or format are not likely to be of interest to any other user, such as files consisting of special purpose aggregations of data for one user.

6 . The Libraries will not purchase or otherwise acquire software for microcomputers that would normally be expected to be owned by individuals for personal use, unless the software fulfills a research or work routine function.

7. Only games with sufficient educational or instructional value for use in coursework will be purchased.

8. Final decisions regarding purchase will rest with the Libraries.

9. Access charges, if any, will be the responsibility of the user not the Libraries. The Libraries should work for the elimination of access charges involving computer software acquired through Libraries' funds. 


\section{Search INFORM}
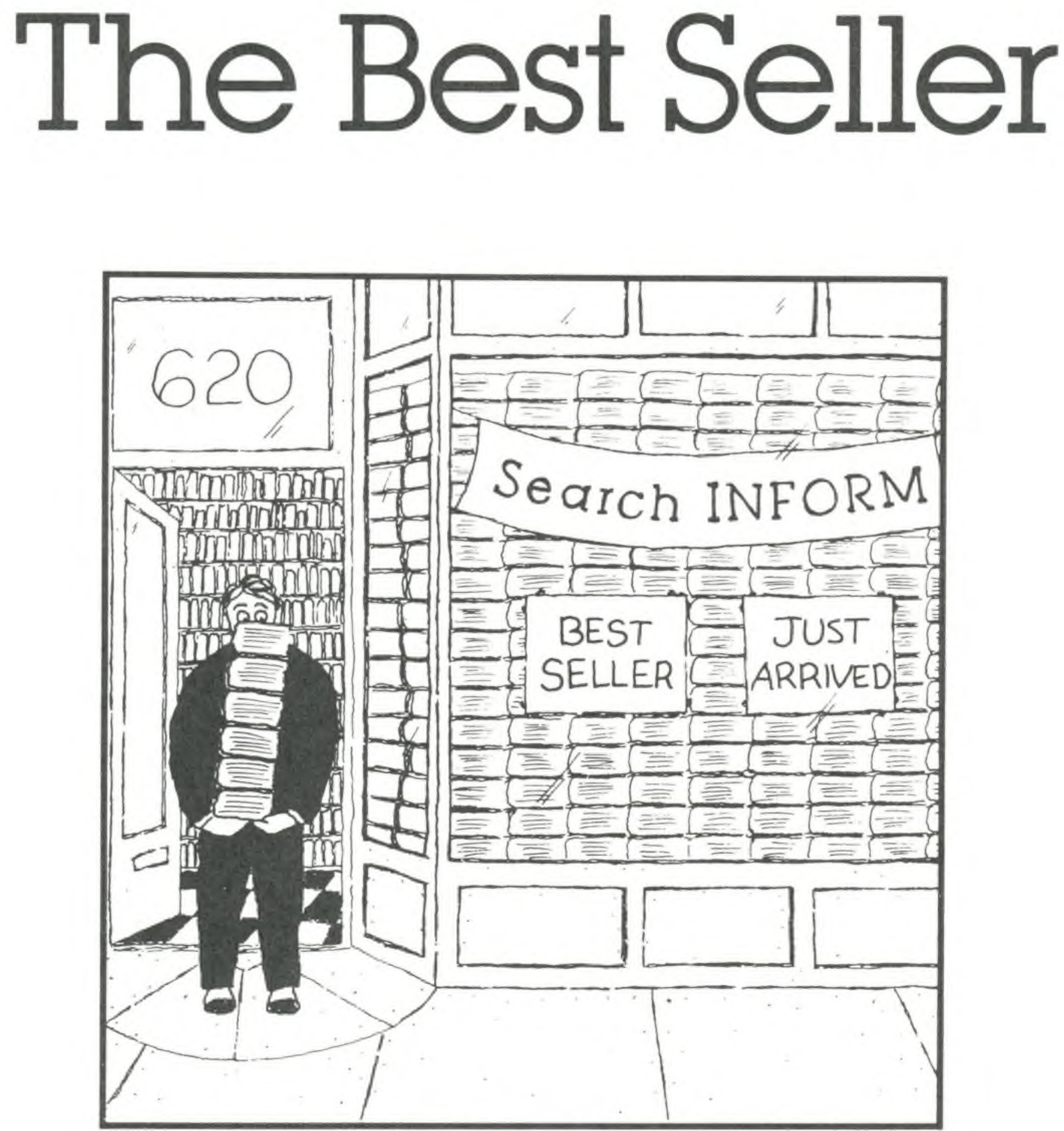

Search INFORM ${ }^{\circledR}$ Data Courier's best seller, just got better. This new, third edition of Search INFORM, the guide to searching the ABI/INFORM ${ }^{\circledR}$ business database, includes:

- Latest ABI/INFORM enhancements - 12 detailed system-specific search guides Indepth system chapters - New company name field - Valuable D-U-N-S numbers - Expanded controlled vocabulary \& rotated terms list - Updated journals list Improved classification code chart Extensive editorial policies - Useful search tips - Unique design - two loose-leaf binders with slipcase.

Order today by calling 800/626-2823 (USA); 800/626-0307 (Canada), or 502/582-4111.

Search INFORM, third edition, \$65.

(Don't wait for the film.) 
APPENDIX D

Handling microcomputer software

1. Microcomputer software may be acquired by one of the following methods: a) purchase from Media Library funds; b) transfer from software purchase funds administered by the Computing Center in cooperation with the University Computing Council and its Software Subcommittee; c) other gift.

2. Microcomputer software is added to the collection and officially cataloged through the normal routines.

3. The first copy of any software purchased, including both documentation and discs, is housed as an archival copy in the Media Library for use only to make authorized copies for circulation or other use.

4 . When a software package is purchased through the Computing Council for use in a laboratory, sufficient copies of software and documentation must be purchased for this use and costs will be borne either by the Computing Center or the Department sponsoring the laboratory as agreed upon by the Computing Council. Laboratory cop- ies will be marked as Media Library copies, and added to the uncataloged inventory.

5. The Computing Center routinely makes available to the Media Library all information (brochures, specifications, etc.) used in purchasing any particular software, including also a copy of the Departmental Copy of the Purchase Order and a copy of any license signed by the Computing Center.

6. The Computing Center advises with the Media Library with regard to licensing prior to purchase.

7. All discs housed in the Media Library are suitably packaged for circulation in order to achieve the highest level of protection for the application: fitted with reinforcement rings, write protected, and labeled to direct users to avoid placing in magnetic fields, extreme heat or cold.

8. When copies of a software program purchased or made for laboratory use are no longer needed in the laboratory, they will be returned to the Media Library for housing or withdrawal.

\title{
Library and information science
}

\section{collections}

\author{
By Margaret E. Galloway \\ Associate Director of Libraries \\ North Texas State University
}

\section{A survey on financing, housing, and staffing of collections for Schools of Library and Information Sciences.}

$\mathbf{I}_{\mathrm{r}}$ the spring of 1986, a survey questionnaire was prepared and mailed to the 56 ALA-accredited library schools in the United States. The purpose of this survey was to identify the source of financing for and the location of the collection which served each accredited library school. A survey with this particular emphasis has not been reported in the literature for a number of years.
Fifty of the 56 questionnaires $(89 \%)$ were completed and returned; of the returned questionnaires, 49 could be evaluated as planned. The questionnaire was comprised of four major questions which examined the source of funding, housing, and servicing of the library school collection. Responses to the four questions are reported below. All 49 respondents answered the initial two ques- 